\title{
LA RELACIÓN NATURALEZA Y SER HUMANO, TECNOLOGÍA Y BIOLOGÍA BAJO LA LUZ DEL POSTHUMANISMO
}

Sasha Cornejo*

\section{Introducción: la paradoja de ser humano}

"Progreso" sigue siendo uno de los motivos centrales por los que se rige nuestra civilización. Pero la actividad transformadora del ser humano ya no solo se limita a su medio ambiente y su entorno, sino también se enfoca paulatinamente a la transformación del ser humano como especie biológica. Esto porque las "ciencias de la vida" posibilitan entrometerse en las bases genéticas y moleculares de los seres humanos e incluso permiten apropiarse de ellas mediante normativas legales cada vez más relajadas de los derechos de propiedad intelectual (Shiva, 2003). Algunos autores han caracterizado este proceso como un nuevo tipo de colonización de la vida a partir de la aplicación tecnológica (Virilio, 1997) (Castoriadis, 2008). Pero lo que merece ser discutido es la idea que la "naturaleza" comenzó un proceso de transformación, conformada como acto de "creación deliberada" y cuando los procesos naturales son dirigidos artificialmente en alianza con la tecnología, difícilmente podremos seguir considerándolos como "naturales". Si deseamos ser justos con los procesos tecnocientíficos y sus alcances no solo en materia tecnológica, sino también biológica, económica y política, necesariamente tendremos que intentar de redefinir lo que entendamos por "lo natural" y "naturaleza". Pero antes, intentemos de circunscribir la noción de "ser humano".
Como un primer acercamiento, desde una concepción epistémica y ontológica "occidental", ser humano puede entenderse como un ente transformador cuya capacidad tecnológica le ha permitido intervenir en los mismos procesos los cuales alguna vez definía como "inviolables", más allá de su intervención". Al parecer la "Cultura" tiende a redefinir continuamente sus límites.

La naturaleza siempre se ha definido como un campo "neutral" y a-histórico, un espacio extra- semiótico sobre el cual la ciencia "natural" aplicaba sus métodos e investigaciones a fin de conocer y explicar sus modos y mecanismos. A su vez, el procedimiento riguroso y objetivo de la ciencia permitía sostener que la naturaleza es real y que existe independiente de la voluntad humana. En este sentido, el concepto de naturaleza soporta no solo una "tradición de pensamiento", -un lenguaje -, sino todo un "mundo", que se ha configurado de tal forma que gran parte de la tradición epistemológica basa en la suposición de su existencia, a la vez, como algo "tangible", -manifestado, por ejemplo, en la existencia de especies biológicas, animales, vegetales y seres humanos-, así también como algo "intangible", -manifestado a su vez, en "leyes naturales" que funcionan independiente de la voluntad humana-. Por lo tanto, la naturaleza no es algo construido por el hombre, sino que siempre está más allá de

\footnotetext{
"Antropólogo. Licenciado en Antropología, Universidad Academia de Humanismo Cristiano. Magíster en Pensamiento Contemporáneo y Filosofía Política, Universidad Diego Portales. El ensayo se enmarca en una profundización de algunos de los temas tratados en el libro "Políticas de la Especie. Eugenesia, ingeniería genética y vida". Pronto a publicar por Ril ediciones. Correo-e: scornejopuschner@gmail.com
} 
las configuraciones conceptuales y epistémicas que el hombre utiliza para comprender y explicarla; la naturaleza es por esencia real. Pero la oposición binaria entre naturaleza "ahí afuera" e historia humana "aquí adentro", se refleja en toda su intensidad y problemática:

Mientras que en los acontecimientos naturales actúa
un movimiento sin finalidad, la historia sería impensa-
ble sin la conciencia de ella. A ella le pertenecen los
elementos, a saber, memoria, planificación, conduc-
ción, dirección, etc. El acontecer natural solo puede
ser observado desde afuera y es significado por noso-
tros, los humanos, de forma mitológica y científica.
La historia, en cambio, es accesible al hombre, hasta
cierto grado desde adentro, en la forma en que intenta
analizar y comprender sus intenciones, tradiciones,
convicciones y metas ${ }^{2}$ (Adhar \& Hülsman, 1989, p. 24).

Pero al parecer, esta distinción entre "dentro" y "fuera" enraizada en la tradición del pensamiento moderno dista mucho de seguir considerándose una obviedad que no requiere explicación ni indagación; esto sobre todo en vista al desarrollo científico y tecnológico actual (Latour, 2007). La definición de ser humano comporta este aspecto paradojal, que, como "ente de dos caras", basa su existencia, por un lado en la naturaleza biológica de sus procesos vitales -su reproducción, vejez y muerte-, y por otro, en el vasto campo de planificación, significación y codificación de los símbolos que constituyen su cultura, permeable al contacto con otras culturas. Pero la historia de la cultura humana también da cuenta de la apertura permanente hacia nuevos espacios semióticos, los que en este contexto pueden ser perfectamente simbolizados por los adelantos científicos de hace dos siglos. Me refiero a la expansión hacia nuevos ámbitos antes desconocidos: desde el espacio interestelar hasta el mundo de los microorganismos. Tanto la historia de la tecnología como de la ciencia comparten una tendencia poco perspicaz al vanagloriar los adelantos técnicos y científicos en vista a las potencialidades y posibilidades que las nuevas invenciones constituyen para el usufructo humano. Es innegable que ha habido adelantos tecnológicos impresionantes y progresos científicos que constituyen verdaderos logros de la inteligencia humana, a parte que estos han ido configurando la propia sociabilidad humana, así como también su permanente relación con su medio ambiente. Sin embargo, la paradójica situación humana se ve reforzada por estos adelantos cada vez más veloces, a tal punto que la propia matriz conceptual, de la cual disponíamos para diferenciar "lo natural" de "lo artificial", comienza a vivir un proceso de fisura que nuestro lenguaje no ha podido aprehender y por tanto nos vemos en serias dificultades a la hora intentar comprender estos procesos.

Sostengo que en la discusión sobre el posthumanismo se pueden encontrar pistas conceptuales que permitan clarificar los sucesos contemporáneos en materia de tecnología y cómo estas definiciones a su vez permean "nuestra" auto compresión como especie biológica y cultural. Este es el aspecto problemático que este artículo se propone indagar, exponiendo una serie de acontecimientos en la teoría contemporánea, fundamentado en cuatro ejes o focos de discusión: 1. Respecto a la discusión sobre el concepto de especie en biología. 2. La tendencia hacia la desmaterialización de los procesos biológicos en concordancia con el paradigma informático en biología. 3. La discusión sobre los procedimientos tecnológicos en relación a la ley de crecimiento exponencial. 4. La respuesta cultural acerca de los límites éticos de la manipulación tecnológica que hoy ocupan cada vez más lugar en la filosofía contemporánea. Lo que 
este trabajo se propondrá mostrar, es que todos estos aspectos teóricos, al parecer dispares, forman parte del horizonte posthumanista y dan cuenta del aspecto paradojal del ser humano que tiende a romper los límites semióticos de su existencia puramente biológica, con lo cual se vuelven borrosas las distinciones clásicas entre naturaleza y cultura en que basa gran parte de la tradición humanista.

\section{Ser humano entre la cultura y la biología.}

Las investigaciones en el campo de la paleontología y la biología evolutiva concuerdan que lo que nos diferencia de las demás especies es nuestra capacidad de raciocinio, el intelecto y el lenguaje. Pero no únicamente las capacidades de abstracción y deducción nos legitiman como "mayores exponentes" de una evolución filogenética sin precedentes y sin comparación con otras especies animales. Pero sobre todo la capacidad de transmitir nuestros conocimientos, fundados en siglos de experiencia inductiva y deductiva; a este "substrato de conocimiento" que configura nuestras percepciones sobre nuestro ambiente y sobre nosotros le dimos el nombre de "cultura". Nadie podría negar la casi obvia idea que como seres humanos somos seres que compartimos una o diversas cultura(s) en sus más variadas expresiones. Para diferenciar al ser humano de otras especies, frecuentemente se cita su rol activo y transformador en relación a su ecosistema. Mientras que las especies no- humanas están limitados a su ecosistema y por tanto dependientes "ecológicamente" de su habitad, el hombre tiende a transformar y apoderarse de su espacio ecológico, delimitando un adentro de un afuera. Ya es un lugar común citar ciertas características físico-anatómicas que contribuyeron al proceso de hominización de nuestra especie, aunque entre todos estos elementos la adquisición del lenguaje y la capacidad de distinguir "relaciones simbólicas" se pueden considerar como un distintivo fundamental del ser humano en relación a otras especies (Deacon, 1997). Pero como sostiene el neuroantropólogo Terrence Deacon, respecto a la co-evolución del lenguaje humano y su cerebro, "no somos más que monos más lenguaje", confiriéndonos esa capacidad de establecer relaciones simbólicas entre los elementos naturales y humanos, lo que a su vez contribuye a la paradójica situación del ser humano inserto en la trama de la evolución (Deacon, 1997).

Como bien nos recuerda Foucault, el concepto de hombre es bastante reciente $^{3}$ y que la pregunta por lo que es el ser humano, comienza tomar forma con las ciencias humanas que conformaron un espacio de saber propio. Por eso preguntar qué es el hombre, es interrogar las similitudes que compartimos como especie biológica y por lo que nos distinguimos de aquellas especies no-humanas ${ }^{4}$.

Sin duda, que la antropología y la paleontología han aportado en cuestionar una universalidad que funcionaba como "garantía" para explicar lo humano en oposición a otras especies. Decir que somos seres culturales o sociales no aporta mucho a una explicación, solo permite circunscribir un lugar en el mundo de este ser que ha roto con toda antigua alianza, tanto con el mundo exterior -la naturaleza-, como con las demás especies. En este sentido, la ciencia occidental nos ha llevado irremediablemente a profundizar el antropocentrismo que fundamenta nuestra paradójica posición en el mundo. Esto también ha conllevado al desprecio sistemático 
no solo de nuestro entorno, sino de las demás especies no-humanas consideradas "inferiores" en la escala evolutiva. La evolución cultural que implica el desarrollo tecnológico actual, también es considerada por muchos filósofos y científicos, un aspecto más del desarrollo evolutivo del ser humano, en este sentido Cultura (con mayúscula) es un dispositivo evolutivo que no ha sido suficientemente problematizado en relación con la propia evolución humana. Sin embargo, la discusión sobre el posthumanismo involucra no solo la preocupación por las transformaciones socioculturales que traen consigo la aplicación de las tecnologías de la vida y la informática, sino sobre todo que involucran y ponen en juego diversos dispositivos de reflexividad en las cuales las propias categorías como "humanismo" y "humanidad" parecen adquirir nuevos sentidos. Así, por ejemplo, ocurre con el concepto de "especie", que como científicos sociales en ocasiones "inexpertos" en temas de biología evolutiva, solemos dar por sobreentendido.

\section{El concepto de especie en la biología.}

Referirse al "ser humano" como lo que es en términos estrictamente biológicos, es referirse a la especie de la cual forma parte y las características compartidas de esta especie. Pero el concepto de especie no resulta ser poco problemático. A pesar que la comunidad científica está de acuerdo en sostener nuestra pertenencia al género homo y a la especie sapiens, los paleontólogos y biólogos evolucionistas aún discuten sobre el concepto de especie, especiación y sobre sus caracteres distintivos (Gould, 1983) (Torreti, 2010). Dado que gran parte de estas consideraciones incumben los procedimientos conceptuales y semióticos, en atención a procesos de diferenciación morfológica y procedimientos taxonómicos aplicados a estos, mediante los cuales los biólogos evolucionistas, etnobotánicos y paleontólogos buscan ponerse de acuerdo sobre cuál concepto de especie resulta más adecuado 5 . Pareciera ser que un concepto tan fundamental como el de especie se encuentra lejos de ser definido en una acepción única y compartida para todas las ramas de las ciencias biológicas. Tal como lo expresa Mayr:

\footnotetext{
Con todo, cada uno de los tres grandes conceptos de especie (tipológico, evolutivo y biológico) tiene, aún hoy, cierta legitimidad en algunas áreas de la investigación biológica. Cuál de ellos se adopte puede depender del tipo de investigación que se haga. El taxónomo de museo, al igual que el estratígrafo, puede hallar muy útil el concepto tipológico de especie, no importa cuán claramente esté refutado por la existencia de especies crípticas y de variantes claramente diferenciadas (phena). Pero cualquiera que trabaje con poblaciones vivientes, en un lugar y un tiempo concretos, encontrará insatisfactorio todo concepto de especie que no sea el biológico. Finalmente, el paleontólogo, parte de cuyo empeño es delimitar taxones de especies fósiles en la secuencia vertical de los estratos, no puede evitar el prestar atención a la dimensión temporal (Mayr, 1992, p. 44).
}

Habrá que resaltar este carácter polisémico del concepto de especie, que no por eso dificulta el propio trabajo científico, pero sí el acuerdo entre biólogos, etnobotánicos y paleontólogos que investigan los distintos aspectos (morfológicos, genéticos, biológicos, evolutivos, etc.) de la vida. Como bien señala Mayr: "todo biólogo trabaja con algún concepto de especie". Y en este sentido el concepto de especie que sea, debe componer los rasgos distintos de la especialidad en cuestión que permitan así sostener, o la diferencia (entre distintas especies), es decir, el factor distintivo o la pertenencia a una misma especie. 
Pero esta problemática se complejiza cuando tratamos de responder a la pregunta sobre la vida humana inserta en la trama de su cultura, de su explicación sobre la vida -mitológicas o científicas-, como también la paulatina transformación de sus condiciones de vida y su "naturaleza"; porque la comprensión sobre lo que somos comporta tanto el factor biológico -expresable en términos de "especie" y "evolución biológica"-, así como la evolución cultural. Sin embargo, la especie humana entendida como el resultado de una evolución biológica, también merece ser discutido por las ciencias sociales.

\section{La oclusión de los cuerpos: biología e informática.}

"The central event of the 20th century is the overthrow of matter. In technology, economics, and the politics of nations, wealth

-- in the form of physical resources has been losing value and significance.

The powers of mind are everywhere Ascendant over the brute force of things".

Dyson, Gilder, Keyword, \& Toffler.

La definición de nuestra humanidad, -sea en su aspecto cultural o biológico -, se ve trastocada por las contribuciones en el ámbito de la ingeniería genética, la nanotecnología y la robótica, los cuales conducen los procesos biológicos irremediablemente hacia un giro paradigmático que se inscriben en una semiótica informática. En los cuerpos individualizados se expresan las características fenotípicas cuya base "informacional" es el genotipo. En este sentido el proyecto del genoma humano, no fue más que un gran proyecto de decodificación, mediante el cual se esperaba aumen- tar las capacidades de comprensión y "lectura" del código genético humano. Hay algo sintomático en este proceso, porque algunas ramas de las tecnociencias naturales tienden hacia la informática como campo de análisis de los data biológicos. Los cuerpos comienzan a ser significados como "textos", que la tecnociencia posibilita entender en su complejidad estructural, además de tender a la re-organización de sus componentes.

Ante esta tendencia, los procesos que están teniendo lugar en relación al desarrollo de las tecnociencias y la ciencia informática más que arrojar nueva luz sobre nuestra auto-comprensión como especie humana, parecen llevar este "proceso de conciencia" hacia un destino insalvable. Esto sobre todo en vista a que estas transformaciones culturales involucran cada vez más a los procesos biológicos, resignificándolos y reconfigurando sus límites tanto epistemológicos y ontológicos. Aunque se entiende que los "procesos naturales", tales como la conformación de un organismo vivo y la heredabilidad de la información contenida en el ADN, ocurren según mecanismos intrínsecos e independientes de toda teleología inherente al proceso evolutivo de las especies ${ }^{6}$; pero estos procesos no solo han conformado un nuevo objeto de decodificación y fuente de información o de "textualidad", como se refleja en el programa de la biología molecular, sino además como un conjunto de mecanismos abiertos a la intervención tecnocientífica de sus componentes químicos, moleculares, celulares y genéticos. Esta tendencia a concebir la biología de los cuerpos como "base informacional", permite a su vez ampliar el ámbito de la virtualidad y la tecnología, incorporándolos cada vez más a los procesos vitales. 
Otro hecho que aparece en la configuración de este horizonte del bío-control es la tendencia a jerarquizar la relación cuerpo-información, en la cual los cuerpos pierden cada vez mayor relevancia cognitiva. En el caso de la biología de los sistemas vivientes, los conceptos de "homeostasis" y "autopoiesis" (Matura \& Varela, 2003; Maturana, 2014) han sido trasladados hacia otros campos de estudio y sobre todo puesto en relación con la teoría cibernética (Bateson, 1998). Estas ponen hincapié en la organización interna de los sistemas vivientes. Así el caso de Maturana y Varela que parten de la hipótesis que "los seres humanos son máquinas vivientes" (2003, p. 66), y la fenomenología que presentan enfatiza en los aspectos internos de organización de los seres vivos. En este sentido, autopoiesis implica un modo de comprensión de la condición para que exista vida que es la delimitación de su entorno?

Las máquinas autopoieticas no tienen entradas ni salidas. Pueden ser perturbadas por hechos externos, y experimentar cambios internos que compensen esas perturbaciones. Si estas se repiten, la máquina puede pasar por series reiteras de cambios internos, que pueden ser o no los mismos. Sin embargo, cualquier serie de cambios internos que se produzca está siempre subordinada a la conservación de la organización de la máquina, siendo esta conservación definitoria de las máquinas autopoieticas (...) puede haber muchas clases distintas de máquina autopoieticas; no obstante, todas ellas serían tales que cualquier interferencia física con su funcionamiento fuera de su campo de compensaciones dará por resultado su desintegración: la pérdida de su autopoiesis (Maturana \& Varela, 2003, pp. 71-72).

El concepto de autopoiesis busca entender el fenómeno de la vida desde mecanismos biológicos intrínsecos de los sistemas vivientes. Pero la tendencia de algunas teorías biológicas va mucho más allá de esto, ya que la tecnifica- ción inherente a las comprensiones científicas de la vida, tienden a concebir la información de manera aislada de los procesos corporales que se expresan en forma de códigos y patrones informáticos o "bits de información", es decir, más allá de la materialidad de la cual surgen y se conforman ${ }^{8}$.

Esto se expresa con fuerza en las ideas de la sociobiología de Richard Dawkins, biólogo que amalgama el proceso de la selección natural con una explicación de la vida y su reproducción centrado en el carácter replicador del gen. En este autor, la definición de gen comporta un aspecto "virtual" que posibilita la replicación de la vida a modo de copia de información digitalizada. El gen entendido como "gen egoísta", fundamental dispositivo que le permite ya no hablar de la vida misma, expresada en entidades concretas y específicas o "individuos", sino más bien del proceso evolutivo mediante la selección y replicación de "genes egoístas": Los cuerpos individualizados sirven de transporte temporal de estos y la información genética se hereda a través de las sucesiones "familiares". En este sentido, se enfatiza en el aspecto evolutivo, determinado por la herencia y el proceso de selección de la información genética contenida en el ADN replicador en detrimento de los individuos concretos.

En las posturas de Dawkins y de Maturana y Varela, incuba un núcleo epistemológico mecanicista inherente a los procesos biológicos en cuestión. Aunque para Dawkins los individuos concretos no resultan del todo insignificantes, pero sí es menguada su importancia ante la longevidad de los genes respecto a los individuos concretos; a tal punto que la selección natural no estaría incidiendo en los organismos autopoieticos, sino más bien en los genes que 
los constituyen ${ }^{9}$. Su postura es un ejemplo interesante del proceso de "desmaterialización" del fenómeno de la vida, ya que el factor determinante de la evolución ya no son los individuos o las especies que surgen, se propagan y pueden perecer mediante procesos de especiación o extinción, sino los genes que comportan el material hereditario de la vida. En su conocido estilo analógico Dawkins señala:

Así como los botes con toda su tripulación ganan o pierden las carreras, en realidad los individuos son los que viven o mueren, y la manifestación inmediata de la selección natural se encuentra, casi siempre, al nivel de los individuos. Pero las consecuencias, a largo plazo, de la muerte de los individuos no sujeta al azar y del éxito de la reproducción, se manifiestan en forma del cambio de la frecuencia en que se encuentran los genes en el acervo génico (...) la evolución es el proceso por el cual algunos genes se tornan más numerosos y otros disminuyen en número en el acervo génico (Dawkins, 1993, p. 54).

La minuciosa segmentación de los cuerpos vivientes en sus elementos "mínimos" o "esenciales" para la vida: el gen, la célula, las proteínas, o el ADN, abren el camino a posibles nuevos reduccionismos (Lewontin, Rose \& Kamin, 2003; Rose, 2009). Pero todo parece indicar que esta "disolución de la vida" es sino una implicación lógica del paradigma cartesiano.

Pero esta paradoja inscrita en la biología evolutiva es solo una muestra de uno de los extremos de esta problemática. Porque pareciera que la biología ha construido parte de sus conocimientos sobre su objeto de estudio -la vida -, tendido entre dos posturas inconmensurables: Por un lado, basado en la idea que la vida se desarrolla mediante un plan fundamentalmente incognoscible para el hombre, es decir la tendencia a la explicación teleológica y el vitalismo ${ }^{10}$, y por el otro, el énfasis en el mecanismo y el funcionamiento de los componentes vitales inherente al materialismo darwinista y al reduccionismo genético.

La pérdida de la importancia de la materia orgánica-corporal-física sobre la desmaterialización de los cuerpos en su aspecto informacional y cibernético configura gran parte de los procesos tecnocientíficos, y es según Katherine Hayles, uno de los distintivos que señalan el paso hacia una condición posthumana. La autora enumera cuatro distinciones de este proceso, del cual solo resaltaremos el primer y el tercer punto:

La visión posthumana privilegia patrones informáticos sobre la creación de instancias materiales, con lo cual la corporeidad de un substrato biológico es más bien visto como un accidente en la historia, más que una inevitabilidad en la formación de la vida (...) la visión posthumana piensa del cuerpo como la prótesis original que todos aprendemos a manipular, de tal forma que extender o re- territorializar el cuerpo a través de otras prótesis significa la continuación de un proceso que empezó antes de nuestro nacimiento ${ }^{11}$ (Hayles, 1999, pp. 2-3).

Pensar la condición posthumana es establecer la relación entre la transformación tecnológica sobre la vida que se configuran en el horizonte de la biología molecular, la ingeniería genética y la nanotencología, así como con el aspecto informacional con la cual paulatinamente se contribuye a un proceso creciente de desmaterialización de los cuerpos biológicos. Esto además conlleva a un proceso creciente de desnaturalización que comportan las propias definiciones de "cuerpo" en vista a su creciente carácter híbrido ${ }^{12}$. 


\section{La condición posthumana y el crecimiento exponencial.}

"Las máquinas de este fin de siglo han convertido en algo ambiguo la diferencia entre lo natural y lo artificial, entre el cuerpo y la mente, entre el desarrollo personal y el planeado desde el exterior y otras muchas distinciones que solían aplicarse a los organismos y a las máqui-

nas.

Las nuestras están inquietantemente vivas y, nosotros, aterradoramente inertes."

Donna Haraway.

Ya en 1984 Donna Haraway escribía en su manifiesto cyborg: "Un cyborg es un organismo cibernético, un híbrido de máquina y organismo, una criatura de realidad social y también de ficción (...) pero las fronteras entre ciencia ficción y realidad social son una ilusión óptica." (Haraway, 1984: 2) Con un claro fin irónico-político la teórica feminista reflexiona sobre las transformaciones que la ciencia provoca en el mismo concepto de especie humana y en particular de "ser mujer". Las definiciones de fronteras ontológicas entre lo "artificial" y lo "humano" comienzan un proceso de borradura, porque en vista a la manipulación bio- tecnológica, quién apele a "fronteras éticas" corre el riesgo de caer en viejos esencialismos. Claramente vivimos una paulatina transformación hacia límites ontológicos borrosos en los cuales las apelaciones a "lo natural" y "lo orgánico" pierden eficacia explicativa. Pero el antiescencalismo mecanicista, sin duda alguna, deja espacios abiertos para la formulación de nuevos determinismos biológicos tanto "geno" o "neurocentristas", pero también permiten concebir una nueva política emancipadora, tal como propone Haraway respecto a la política cyborg ${ }^{13}$.
En este sentido, se puede entender que la condición posthumana se configura bajo la tensión entre la definición de los límites ontológicos de lo "humano", lo "animal" o lo "artificial" y una política de emancipación que busca darle un sentido político a estas transformaciones. Esto significa vislumbrar el potencial tecnológico a partir del momento histórico "singular" en que la configuración, a modo de "enhancing", de nuestras características bío, psico y fisiológicas, nos permitirá, como especie, moldear un futuro proyectado, tanto para nuestra longevidad y nuestras aptitudes físicocognitivas ${ }^{14}$. En este sentido, la evolución cultural que conlleva inevitablemente esta evolución tecnológica se inserta en la reflexión sobre la evolución humana. Es probable que la evolución cultural ha dejado de ser en su expresión un asunto de "selección natural", trascendiendo gran parte de sus finalidades adaptativas. Más bien, la evolución cultural, a través de los avances veloces en materia tecnológica, comienza a ser concebida como parte inexorable de un proceso evolutivo inevitable, el cual va a tender hacia un control cada vez más perfeccionado de los mecanismos que subyacen a los procesos vitales. Esto se expresa con fuerza en el programa de la nanotecnología:

Los principios, fuertemente enraizados, del cambio evolutivo, darán forma al desarrollo de la nanotecnología, incluso irán borrándose las distinciones entre hardware y vida. Estos principios mostrarán cuanto podremos esperar lograr y cuanto no, y nos podrán ayudar a enfocar nuestros esfuerzos para formar el futuro. Ellos también nos dicen mucho sobre lo que podremos o no podremos prever, porque ellos guían la evolución no solo del hardware, sino del conocimiento mismo ${ }^{15}$ (Drexler, 1986, p. 33). 
Esta disciplina de investigación, junto a la robótica y la informática, configuran los ejes paradigmáticos con los cuales se espera no solo superar las limitaciones biológicas, sino que ante todo marcan el acontecimiento que da cuenta de la obsolescencia del cuerpo biológico (Sibilia, 2009). Esto es el resultado de la evolución tecnológica, expresado en el paradigma de la aceleración exponencial ${ }^{16}$ (Kurzweil, 2008), la cual sostiene que el avance tecnológico trascenderá los límites biológicos e incluso que las máquinas inteligentes podrán mejorarse a sí mismas ${ }^{17}$. Por lo mismo que para la inteligencia humana va a resultar difícil siquiera concebir e imaginar las posibilidades tecnológicas futuras. La cultura humana que ha posibilitado este desarrollo puede entenderse aquí como fuente de creación de prótesis, -prótesis tecnológicas-, símbolo y metáfora de un futuro porvenir que a creciente velocidad traza las posibilidades que la tecnología abre para la "auto-transformación" humana. Así como señala Ray Kurzweil para uno de los tantos aspectos de esta transformación:

(La) biología tiene limitaciones inherentes. Por ejemplo, cada organismo vivo tiene que ser construido a partir de proteínas que están plegados a partir de cadenas unidimensionales de aminoácidos. Mecanismos basados en proteínas carecen de fuerza y velocidad. Podremos hacer una reingeniería de todos los órganos y sistemas de nuestro cuerpo biológico y cerebros para ser mucho más capaz (...) Junto con el ciclo de mejora de la aceleración de la inteligencia no biológica, la nano-tecnología permitirá la manipulación de la realidad física a nivel molecular ${ }^{18}$ (Kurzweil, 2008, p. 33).

Una vez superada toda barrera de tipo esencialista u otras nociones de tipo teleológicas que puedan de una u otra forma, configurar barreras éticas ${ }^{19}$ a los sueños de control y tecnologización de la vida misma, será posible extender el potencial de la intromisión tecnológica sobre los cuerpos. Pero esta "disolución" de los cuerpos orgánicos ya albergaba en los intersticios de la ciencia tecnificada ${ }^{20}$. Esto puede ser evidenciado empíricamente en la ley de Moore ${ }^{21}$ y en la noción de crecimiento exponencial de la tecnología en que basan gran parte de las expectativas de los investigadores en nanotecnología y robótica. Aunque existen amplias dudas y temores sobre este escenario futuro - discutidas y problematizadas en los círculos bioéticos y filosóficos-, la tendencia de estos procesos sugiere la paulatina configuración de un horizonte posthumano. Tal lo concibe, por ejemplo, el concepto de "singularidad" que propone Ray Kurzweil y que basa en una idea optimista del desarrollo tecnológico. La singularidad, marca el punto de ruptura y de no retorno del momento en que la tecnología comience a configurar las características humanas en vistas a "mejoras". Mientras que las características corporalesorgánicas del ser humano son concebidas en términos de "limitaciones biológicas", la tecnología tenderá a superar estas limitaciones:

\footnotetext{
La singularidad representará la culminación de la fusión de nuestro pensamiento biológico y la existencia con nuestra tecnología, lo que resulta es un mundo que sigue siendo humano, pero que trasciende nuestras raíces biológicas. No habrá distinción post- Singularidad, entre el ser humano y la máquina, o entre la realidad física y virtual. Si usted se pregunta lo que quedará inequívocamente humana en un mundo así, es simplemente esta cualidad: la nuestra es la especie que busca extender su alcance físico y mental más allá de las limitaciones actuales ${ }^{22}$ (Kurzweil, 2008, pp.17-18).
}

El desarrollo nanotecnológico posibilitaría la intromisión microscópica al cuerpo biológico con la cual se espera revertir nuestras limitaciones, incluyendo la vejez, con esto la fusión hombre-máquina ya no sería tan solo una imagen soñada por algunos escritores de cien- 
cia ficción. La nanotecnología permitiría dar uno de los primeros pasos hacia esta fusión posthumana, que supone la extensión del dominio de la máquina corporal-física-neuronal con la extensión proteica de las máquinas artificiales. Un híbrido orgánico-tecnológico:

\section{Supongamos ahora que fuera posible remplazar cada célula de su cerebro por un circuito integrado de computadora, especialmente diseñado, que realizara las mismas funciones y que interconectamos estos dispositivos exactamente en la misma forma en que están conectadas sus células cerebrales. Si la colo- camos en el mismo ambiente, esta nueva máquina sería capaz de reproducir los mismos procesos que se producen dentro de su cerebro (Minsky, 1986, p. 300).}

Como es de suponer, el debate actual sobre el posthumanismo involucra una discusión amplia sobre los alcances éticos de la aplicación biogenética y nanotecnológica a los sistemas vivientes. Se tiende a agrupar a los defensores bajo la categoría de "transhumanistas" y a los detractores como "bioconservadores". Sin embargo, esta distinción es demasiado simplista para comenzar a entender los matices de una u otra postura. Filósofos como Jürgen Habermas, Hans Jonas y Francis Fukuyama han enfatizado en las dudas acerca del peligro de la intervención genética con fines eugenésicos, que claramente apuntan hacia el perfeccionamiento de las capacidades y aptitudes humanas (sea cognitiva o física), y que provocarían serios desafíos a nuestra definición de especie humana. Mientras que la mirada crítica de Habermas (2002) radica en la transformación de la auto comprensión como especie humana, basada en ciertos principios rectores "humanistas" de igualdad, que inevitablemente se verán fuertemente trastocadas con la manipulación biogenética; en tanto que la preocupación de Fukuyama (2004), si bien similar, radica en la re-definición de la "dignidad humana", amenazada cuando unos pocos individuos serán genéticamente "mejorados". ¿Qué estatus jurídico adquirirán esos individuos manipulados ante aquellos que no han sido intervenidos? Si bien estas posturas tienden a sobreestimar las capacidades manipulativas del ser humano, basan en viejos ideales humanistas, principios rectores de "civilidad" de la cultura occidental; así como en una concepción epistemológica que ve en la borradura de los límites entre tecnología humana y biología una amenaza a la propia existencia humana, basada en límites ontológicos precisos y definidos. En vista de esto, "ser humano" ya no significaría lo mismo en el momento en que apliquemos la tecnología para mejorar nuestras capacidades físicas o cognitivas.

\section{Posthumanismo y cultura.}

"La especie humana puede, si lo desea, trascenderse a sí misma

-no sólo esporádicamente, un individuo aquí de cierta manera, un individuo ahí de otra- sino en su totalidad, como humanidad.

Necesitamos un nombre para esta nueva creencia. Tal vez transhumanismo servirá: el hombre permaneciendo hombre, pero transcendiéndose mediante la realización de nuevas posibilidades de y para su naturaleza humana".

Julian Huxley.

A pesar que la discusión sobre el posthumanismo data de fechas recientes, la irrupción de esta temática en el campo de la filosofía tomó una forma particular con la disputa acaecida a comienzos del año 2000, cuando el filósofo alemán Peter Sloterdijk encaró la posibilidad 
de mejorar las aptitudes físico/cognitivas del ser humano a partir del uso de la tecnología. Esto generó una avalancha de reacciones de la población alemana y en especial algunos de sus filósofos más respetados, entre ellos el propio Habermas.

Sloterdijk problematiza en su polémica conferencia el concepto de "domesticación" ("Züchtung") arraigado en la conciencia europea, en relación al cultivo de la "alta cultura", heredera de los ideales ilustrados. Sostiene que el humanismo basa gran parte de sus pretensiones "cultivadoras" en el desarrollo de la "alta cultura", eco de una vieja tradición eurocéntrica ${ }^{23}$. Sin embargo, estos "ideales civilizatorios", ante las nuevas tecnologías tanto "de la vida" como de la "información" -hoy la internet y las redes de telecomunicaciones-, se encuentran sujetos a profundos cambios que la propia filosofía no puede desconocer ${ }^{24}$.

La correspondencia entre domesticación y civilidad, ("eticidad "en términos kantianos) alberga gran parte del núcleo del humanismo y atañe a su vez, el carácter creativo y autotransformador del ser humano. El concepto de antropotécnicas parece apuntar a esta cuestión ${ }^{25}$. En su interpretación de Heidegger y con el auxilio del Zaratustra de Nietzsche, Sloterdijk sostiene: "el humanista deja primero que le den al hombre para después aplicarle sus métodos domesticadores, adiestradores, educadores, convencido como está de la necesaria relación entre leer, estar sentado y apaciguarse" (Sloterdijk, 2006, p. 63).

Aquí Sloterdijk sigue a Nietzsche como crítico y opositor del carácter domesticador de la cultura.
El recelo de Nietzsche frente a toda la cultura humanística exige que se airee el secreto de la domesticación de la humanidad. Él pretende llamar por su nombre a los que hasta ahora han ostentado el monopolio de la cría - los curas y los profesores, que se presentaban como los amigos del hombre (Sloterdijk, 2006, p. 64).

En esto algunos intérpretes contemporáneos parecen coincidir con la lectura de Sloterdijk sobre Nietzsche ${ }^{26}$, a saber, su crítica a la cultura humanística basada en la diferencia entre domesticación y amansamiento, reflejo de una moral pastoral que detentaba el monopolio de la formación del hombre como bestia amansada. Respecto a esto, que es innegable el carácter "tecnológico" del propio saber, como "tecnología de amansamiento" y con ello, la evidencia del poder inmanente a los procesos culturales. Sin embargo, volviendo al humanismo criticado por Heidegger, la lectura de Sloterdijk antepone la evidencia del carácter animal del ser humano ante la conciencia de su propia maleabilidad, conducción, cría y domesticación.

\begin{abstract}
Es el signo de los tiempos de la técnica y la antropotécnica que, cada vez más, los hombres van a parar por casualidad a la parte activa o subjetiva de la selección, incluso sin haber tenido que esforzarse intencionadamente por alcanzar el papel del seleccionador. Cabe además afirmar lo siguiente: existe un malestar en el poder de elegir, y pronto llegará a ser admisible como opción por la inocencia que los hombres se nieguen explícitamente a ejercer el poder de selección después de haber luchado realmente por conseguirlo (Sloterdijk, 2006, p. 70).
\end{abstract}

Es probable que este haya sido uno de los pasajes más escandalosos de la lectura de Sloterdijk, en vista a la sensibilidad alemana ante estos temas después del programa de la higiene racial y la eugenesia nazi. Pero lo cierto es que el proceso de la modernidad puede ser 
"leído" en esos términos, como la liberación constante y permanente no solo de nuestras limitaciones cognitivas (donde gran parte de la historia de la ciencia dan cuenta de esto), o las limitaciones físicas (desde la prótesis hasta la aplicación de nanotecnologías), nos introducen a un campo problemático que enfrenta la dimensión ética y moral de los límites acordados por la tradición judeocristiana ${ }^{27}$.

\section{Algunas palabras finales}

Encarar la problemática postuhumanista inevitablemente supone forzar el viejo dualismo cartesiano enraizado en gran parte en la tradición de pensamiento occidental. Esto arroja una serie de problemas y contradicciones ya que desde nuestro lenguaje que hemos separado los ámbitos ontológicos ${ }^{28}$ entre un "afuera" y un "adentro", entre la cultura humana y la naturaleza. Pero hoy nuestro propio lenguaje ya no parece ayudarnos del todo para entender y significar las transformaciones que realizamos en el mundo, por ello será necesario buscar una terminología adecuada que nos permita, quizás no resolver el problema del dualismo, sino obviarlo para no caer en sus trampas.

No es únicamente un problema de "paralaje" el que media gran parte de los conocimientos acerca del fenómeno de la vida, sino más bien estriba en un punto nodal de la concepción epistemológica que fundamenta la construcción del conocimiento científico. La tradición del naturalismo aún constituye una de las creencias fundamentales compartidas por la comunidad científica. Gran parte de la jerarquía de las ciencias basa en la distinción entre el ser humano "cognosciente" y la naturaleza "ahí afuera" dispuesta a ser explicada o comprendida ${ }^{29}$. Pero hoy debemos ser conscientes que esta definición no puede entenderse de forma universal, más bien constituye una particularidad de la cultura occidental moderna. Sin embargo, en la actualidad desde el mismo campo de las tecnociencias surge la problemática posthumanista como una "gran interrogante" surgida desde el núcleo mismo de la cultura occidental y moderna, en la cual se vuelve a plantear el problema de los determinismos técnicos en vista al potencial transformador de la tecnología y las bio-ciencias sobre la cultura y la evolución biológica del ser humano.

Lo que, a fin de cuentas, interesaba problematizar en este artículo, es la idea que el ser humano es producto no solo de su historia, sino también resultado de su intervención en lo que semióticamente definía como "externo" a su cultura, -lo que comúnmente denominamos "naturaleza"-, así como también se vuelve un producto maleable tanto por la profundidad del dominio que ejerce sobre el mundo, como del control sobre sus propios procesos vitales, biológicos, genéticos y moleculares. Esto sin duda suscita una interpretación antropocéntrica. Por eso que concebir la cultura como un conjunto de "antropotécnicas" nos permitiría, a su vez, concebir al ser humano como productor y producto de la tecnología humana. Por esa razón es que podemos sostener que la "naturaleza humana" es un oxímoron, una contradicción de los términos, ya que "humanidad" y "naturaleza" se oponen drásticamente en sus definiciones ${ }^{30}$. Además, porque todo indica que el carácter alterable de nuestra naturaleza supone el abandono de un esencialismo fuertemente enraizado en una concepción de ser humano heredada por los siglos de historia de la filosofía occidental. Desde la filosofía de Aristóteles hasta Hobbes y Rousseau que al 
ser humano se le adjudicaba ciertas características esenciales que lo distinguían de otras especies no- humanas. Como ya hemos visto, gran parte de estas ideas siguen vigentes a la hora de distinguir nuestra especie de otras, sin embargo, resulta difícil sostener actualmente el mismo criterio de "estabilidad" como una característica de la "esencia humana". Este criterio de lo invariable se ve fuertemente trastocado en vista al proceso evolutivo de nuestra cultura como dispositivo de adaptación. Esto en vista a que los programas tecnológicos de

\section{Notas}

\footnotetext{
${ }^{1}$ La pregunta que surge aquí, es si este "más allá" es de tipo "normativo", fundado en el deber por lo tanto, en el grado de intervención éticamente posible y permisible; o es de tipo "históricocultural", fundado en las capacidades tecnológicas cada vez más creciente de intervenir en los procesos naturales a fin de modificarlos, dirigirlos y controlarlos. En este sentido que la pregunta por el "más allá" plantea un problema filosófico que no solo es epistemológico, sino que incumbe una antropología, es decir, una determinada concepción de ser humano.

2 "Während im Naturgeschehen ein unabsichtliches Anderswerden wirkt, ist die Geschichte ohne das Bewußtsein um sie nicht denkbar. Zu ihr gehören die Elemente Wissen, Gedächtnis, Planen, Leiten, Lenken, usw. Das Naturgeschehen kann daher nur von außen betrachtet werden und wird von uns Menschen mythologisch und wissenschaftlich gedeutet. Die Geschichte dagegen ist dem Menschen bis zu einem gewissen Grade von innen zugänglich, indem er sich, seine Absichten, Traditionen, Überzeugungen und Zeilvorstellungen analysiert und versucht sie zu verstehen".

${ }^{3}$ Foucault señala en "Las palabras y las cosas": "El campo epistemológico que recorren las ciencias humanas no ha sido prescrito de antemano: ninguna filosofía, ninguna opción política o moral, ninguna ciencia empírica, sea la que fuere, ninguna observación del cuerpo humano, ningún análisis de la sensación, de la imaginación o de las pasiones ha encontrado jamás, en los siglos XVII y XVIII, algo así como el hombre, pues el hombre no existía (como tampoco la vida, el lenguaje y el trabajo); y las ciencias humanas no aparecieron hasta que, bajo el efecto de algún racionalismo presionante, de algún problema científico no resuelto, de algún interés práctico, se decidió pasar al hombre (...) al lado de los objetos científicos (...) aparecieron el día en que el hombre se constituyó en la cultura occidental a la vez como aquello que hay que pensar y aquello que hay que saber." (Foucault, 2008, pp. 334-335) Todo parece apuntar que los trabajos posteriores de este filósofo, desde la historia de la locura hasta los
}

la bío y nanotecnología suponen la intervención directa en los cuerpos biológicos, en la cual los artefactos sirven de nuevas prótesis para la mejora (enhancement) de las características humanas. Abordar esta problemática nos lleva a plantear los límites éticos permisibles que la bioética ya ha discutido fervientemente, pero que las propias ciencias sociales deberán encarar por las profundas transformaciones que estas significan y significarán cada vez más para nuestra cultura.

procedimientos de castigo en la temprana modernidad, apuntaban a investigar la forma en que se llenó de contenido este lugar "vacío" llamado "ser humano" y cómo surgió esta problemática a la par del nacimiento de las técnicas modernas de disciplinamiento.

${ }^{4}$ Aquí la distinción entre las acepciones cada vez más utilizadas de "humano" y "no-humano" (Latour, 2007) (Descola, 2001), no persiguen forzar las "barreras epistemológicas" heredadas por la modernidad, sino llamar la atención del aspecto "relacional" mediante los cuales lo humano se define en relación a lo no-humano. Desde la visión occidental, lo no- humano representa el mundo orgánico "natural" del cual los humanos se independizaron. Sin embargo la relación entre naturaleza y cultura ha suscitado diversas interpretaciones en la historia de las ciencias sociales, sobre todo en la antropología desde los años noventa a partir de la escuela de Phillipe Descola. Mientras que el traspaso de la naturaleza a la cultura es vista por unos como "quiebre", como en gran parte de la tradición de la antropología cultural y las ciencias sociales (por ej. en Freud y LeviStrauss); por otros es entendido como "continuidad" que se suma como un aspecto más a la evolución biológica humana (como en el caso de los sociobiólogos R. Dawkins y E. O. Wilson). Sin embargo, en el campo de la antropología cultural se ha problematizado más a fondo la suposición de una naturaleza independiente. Como sostiene la antropóloga Roy Ellen: "Las conceptualizaciones de la naturaleza no son invención de individuos (...) sino que surgen a través de la contingencia histórica, las limitaciones lingüísticas, la extensión metafórica, las prohibiciones rituales, etc. Como parte de sistemas de creencias, son producto de interacciones, adiciones, elaboraciones y condensaciones. La existencia de contradicciones e inconsistencias se debe a que la naturaleza es a la vez una categoría simbólica abstracta y una categoría cognitiva no- básica, al mismo tiempo un modelo "del" mundo (una representación) y una modelo "para" (un plan de acción) (Geertz, 1966) y es precisamente esa capacidad de pasar de uno a otro, de interactuar con el medio 
ambiente y distanciarse de él, lo que nos distingue de los primates no-humanos" (Ellen, 2001, p. 162).

${ }^{5}$ Esto demuestra que el "lenguaje común", la "conmensurabilidad paradigmática" en el sentido kuhniano de concebir los paradigmas cientííicos también como "acuerdos" entre los científicos al compartir un lenguaje (es decir un cúmulo de conceptos) aceptado y comprendido a modo consensual, resulta no del todo convincente, sobre todo aplicado al vasto programa de estudio de la biología.

${ }^{6}$ Esta es la interpretación de Mayr (1992) sobre el real impacto que tuvo el evolucionismo darwinista en la ciencia biológica y uno de los aspectos que significó mayor resistencia incluso entre biólogos que aceptaban la teoría propuesta por Darwin, pero difícilmente abandonarían la creencia en alguna fuerza inmaterial o vitalista que animara los cuerpos. Respecto a esto Maturana y Varela sostienen: "De ahí que, bajo la presión inevitable de la experiencia y el impulso decisivo del pensamiento cartesiano, emergiera un enfoque distinto, y que el mecanismo ganara paulatinamente el mundo biológico, al insistir en que los únicos factores operantes en la organización de los sistemas vivos son los factores físicos y negar la necesidad de alguna fuerza inmaterial organizadora de lo vivo. En efecto, ahora parece evidente que, una vez que se lo ha definido adecuadamente, cualquier fenómeno biológico puede describirse como surgido de la interacción de procesos físico-químicos cuyas relaciones son especificadas por el contexto de su definición" (Maturana \& Varela, 2003, pp. 63-64).

${ }^{7}$ Es necesario enfatizar que la fenomenología propuesta por Maturana y Varela (2003) apunta hacia "individuos discretos" y no al aspecto "especie" como ha sido la tendencia desde el darwinismo y sus tardías formulaciones. Por lo tanto, el eje central del análisis son los individuos concretos que viven bajo condiciones específicas, y no la "generalización" de estos individuos englobados en un concepto de especie. Sin embargo, los autores son conscientes de que esto a su vez implica un giro epistemológico para las ciencias biológicas.

8 "Because information had lost its body, this construction implied that embodiment is not essential to human being. Embodiment has been systematically downplayed or erased in the cybernetic construction of the posthuman in ways that have not occurred in other critiques of the liberal humanist subject, especially in feminist and postcolonial theories" (Hayles, 1999, p. 4).

9 "Su inmortalidad potencial hace del gen un buen candidato como unidad básica de selección natural. Ha llegado ahora el momento de subrayar la palabra «potencial». Un gen puede vivir durante un millón de años, pero muchos genes nuevos ni siquiera logran superar su primera generación. Los escasos genes que tienen éxito lo deben, en parte, a la suerte, pero sobre todo a que tienen lo que se requiere, y ello significa que son aptos para fabricar máquinas de supervivencia. Producen un efecto en el desarrollo embrionario de cada cuerpo sucesivo en que se encuentran, de tal manera que dicho cuerpo tiene algunas pequeñas posibilidades más de sobrevivir y de reproducirse que las que tendría bajo la influencia de un gen rival o alelo" (Dawkins, 1993, p. 45).

${ }^{10}$ El filósofo francés Henry Bergson, discute el problema del vitalismo en relación a la aplicación de la inteligencia humana sobre la materia inerte: "La ciencia positiva es, en efecto, obra de pura inteligencia. Ahora bien, se acepte o se rechace nuestra concepción de la inteligencia, hay un punto que todo el mundo nos aceptará, es que la inteligencia se siente a gusto sobre todo en presencia de la materia no organizada. De esta materia saca cada vez mejor partido a través de invenciones mecánicas, y estas se le vuelven tanto más fáciles cuanto más mecánicamente piensa la materia (...) ahora bien, cuando la inteligencia aborda el estudio de la vida, necesariamente trata lo viviente como lo inerte" (Bergson, 2007, p. 206). La argumentación que Bergson construye, se sintetiza en el concepto de elan vital, que marca el punto de ruptura de la inteligencia al momento de intentar comprender científicamente el fenómeno de la vida.

11 "The posthuman view privileges informational pattern over material instantiation, so that embodiment in a biological substrate is seen as an accident of history rather than an inevitability of life (...) the posthuman view thinks of the body as the original prosthesis we all learn to manipulate, so that extending or replacing the body with other prostheses becomes a continuation of a process that began before we were born".

${ }^{12}$ En sintonía con lo señalado, la investigadora argentina Paula Sibilia, escribe: "Lanzado a las nuevas cadencias de la tecnociencia, el cuerpo humano parece haber perdido su definición clásica y su solidez analógica: en la estera digital se vuelve permeable, proyectable, programable" (Sibilia, 2009, p. 14).

${ }^{13}$ La política cyborg busca romper con la serie de dualismos superados por la creciente tecnificación de la sociedad humana. Haraway desarrolla un sustrato político-ontológico que fundamenta una emancipación del movimiento feminista más allá de los viejos dualismos que descansan en la base tanto del marxismo, como del viejo feminismo. Para eso será necesario encarar críticamente el desarrollo científico y tecnológico ya que paulatinamente los viejos lenguajes de la naturaleza y la cultura se tornan obsoletos. Con un guiño hacia la ciencia ficción feminista, busca extraer las figuras amenazantes del viejo orden dual que hoy está en crisis. Su propuesta es: "prefiero ser cyborg que reina". El cybrog está en los bordes y límites de nuestro pensamiento, una apertura hacia una alteridad radical y nueva que necesita ser pensada y llenada de contenido.

${ }^{14}$ Kurzweil con un claro dejo evolucionista, establece 6 épocas que distinguen distintos momentos evolutivos: La "época uno" (Física y química), está caracterizada por la formación de las estructuras de base de la materia y la energía; la "época dos" (Biología y ADN), se distingue por la formación de la vida y la capacidad de almacenar información hereditaria; la "época tres" (el cerebro), por la capacidad de generar modelos mentales del mundo; la "época cuatro" (tecnología) está centrada en la idea de la capacidad racional y el aumento de las facultades humanas que le significó el dedo oponible. Este desarrollo además le valió a la especie humana un considerable aumento de capacidad craneana y un desarrollo más veloz de sus capacidades físicas y mentales (calculada a modo logarítmico); la "época cinco" (la fusión de la tecnología humana con la inteligencia 
humana), se distingue por el comienzo de la "singularidad": "Esto será el resultado de la fusión de la gran conocimiento incorporado en nuestros propios cerebros con capacidad mucho mayor, la velocidad y el intercambio de conocimientos capacidad de nuestra tecnología.(...) La singularidad nos permitirá superar antiguos problemas humanos y amplificar enormemente la creatividad humana. Vamos a preservar y mejorar la inteligencia de que la evolución nos ha dado, (a partir de) (...) la superación de las profundas limitaciones de la evolución biológica" (Kurzweil, 2008, pp. 28-29). La "época seis" consiste en el despertar inteligente del universo.

15 "The deep-rooted principles of evolutionary change will shape the development of nanotechnology, even as the distinction between hardware and life begins to blur. These principles show much about what we can and cannot hope to achieve, and they can help us focus our efforts to shape the future. They also tell us much about what we can and cannot foresee, because they guide the evolution not only of hardware, but of knowledge itself."

${ }^{16}$ En sintonía con la ley de Moore, el crecimiento exponencial que propone Kurzweil a partir de la exposición de una serie de datos empíricos expuestos en curvas exponenciales, que da cuenta y analiza la aceleración paulatina del desarrollo tecnológico. Esto se opone a una visión de desarrollo evolutivo de tipo "lineal" donde las mejoras en tecnología se suman a otras, produciendo un avance menos acelerado de este proceso. En cambio, el crecimiento exponencial no es solo "aditivo", sino más bien, "multiplicador". La aceleración de este proceso implica que cada invento y cada "mejora" se puede trasladar a otros campos de estudio y aplicación. En este sentido Kurzweil resalta el factor "cooperativo" de las ciencias informáticas con la robótica y la nanotecnología. Según Kurzweil "el crecimiento exponencial es una característica de cualquier proceso evolutivo, de los cuales la tecnología es un ejemplo primario. Se puede examinar los datos de diferentes maneras, en diferentes escalas de tiempo, y para una amplia variedad de tecnologías, que van desde la electrónica a la biológica, así como por sus consecuencias, que van desde la cantidad de conocimiento humano con el tamaño de la economía. La aceleración del progreso y el crecimiento se aplica a cada uno de ellos. De hecho, a menudo nos encontramos con un crecimiento exponencial no solo simple, pero el crecimiento exponencial "doble", lo que significa que la tasa de crecimiento exponencial (es decir, el exponente) es en sí misma un crecimiento exponencial" (Kurzweil, 2008, pp. 20-21).

${ }^{17}$ La "auto mejora" ("self-improving") de las máquinas es una de las características que se prevé para el futuro de la inteligencia artificial. Al respecto Kurzweil señala: "Una vez que las máquinas alcanzan la capacidad de la tecnología de diseño e ingeniero como lo hacen los humanos, solo mucho más alto en velocidades y capacidades, tendrán acceso a sus propios diseños (código y fuente) y las posibilidades de manipularlos. Los seres humanos están ahora por lograr algo similar a través de la biotecnología (cambio de los procesos de información y genéticos que subyacen a otra nuestra biología), pero de una manera mucho más lenta y mucho más limitada que lo que las máquinas serán capaces de lograr mediante la modificación de sus propios programas" (Kurzweil, 200, p. 33). Sin embargo, es de notar que las discusiones en el campo del posthumanismo en ocasiones raya en la ciencia ficción, tal como lo demuestra la respuesta de Nicholás Agar a Nick Bostrom. La preocupación de Bostrom acerca del desarrollo de la inteligencia artificial (IA) se basa en la idea que esta nos podría llevar a la extinción como especie humana, dado el perfeccionamiento creciente de las máquinas. El temor de Bostrom es que la IA -si es que el ser humano no resuelve los problemas acerca del control de este desarrollo, y dado la capacidad de automejoramiento de la IA-, pueda tender a una "superinteligencia" que amenazaría la existencia de los propios seres humanos. Agar contra argumenta que la retórica alarmista no debe limitar el desarrollo de la IA, siempre y cuando el manejo de riesgos que conlleva este proceso se lleve a cabo de forma racional. Agar parece confiado que los problemas surgidos mediante estos desarrollos tecnológicos se pueden resolver a medida que se avanza en la sofisticación de nuevas tecnologías de IA, sobre todo porque los beneficios son demasiado grandes como para abandonar este programa (Véase Agar, 2016).

18 "Biology has inherent limitations. For example, every living organism must be built from proteins that are folded from onedimensional strings of amino acids. Protein-based mechanisms are lacking in strength and speed. We will be able to reengineer all of the organs and systems in our biological bodies and brains to be vastly more capable".

${ }^{19}$ La permanente tensión entre ética y ciencia ha configurado una serie de discusiones sobre todo en el transcurso del desarrollo de la ciencia y la tecnología humana, por ejemplo Hans Jonas (1984) en su libro El principio de responsabilidad construye un llamado de atención a la ciencia de volver éticos sus procedimientos, sobre todo en vista a una responsabilidad con las futuras generaciones. Sin embargo, con el primer Wittgenstein el campo científico se define en su lejanía al campo ético. Para esta etapa de su pensamiento, el filósofo austríaco pensaba que ambos, tanto ciencia como ética recorren caminos distintos que no deberían mezclarse. Por otra parte, apelando a una nueva ética del conocimiento, el biólogo francés Jaques Monod, señala: "Las sociedades modernas, tejidas por la ciencia, viven de sus productos, han devenido dependientes como un toxicómano de su droga. Ellas deben su poderío material a esta ética fundadora del conocimiento, y su debilidad moral a los sistemas de valores, arruinados por el mismo conocimiento, a los que intentan aún atenerse. Esta contradicción es mortal" (Monod, 1993, p. 187).

${ }^{20}$ Epistemológicamente las barreras han sido permanentemente traspasadas porque quizás nunca hubo en realidad barreras "firmes y duraderas", porque la ciencia ha tendido, en palabras de Heidegger, hacia "lo gigantesco" y la "exageración" (Heidegger, 2015). Heidegger veía en el dominio científico la realización de una proyección tecnológica sobre el mundo: el dominio de la planificación, la matematización y el cálculo, se expresa con claridad en el proceder 
tecnocientífico. Lo que este filósofo no pudo prever, es la tendencia hacia la virtualidad, el diseño y lo informático, propio de la era digital que hoy asistimos y que viene a re-configurar gran parte del conocimiento sobre los sistemas vivientes.

${ }^{21}$ La ley creada por Gordon Moore señala que cada dos años se duplica tanto el número de transistores en un procesador a la vez que el costo asociado tenderá a disminuir. Esto daría por resultado que a medida que el desarrollo tecnológico avanza, bajarían tanto los costos de las computadoras y aumentarían las capacidades de memoria y velocidad de los procesadores.

22 "The Singularity will represent the culmination of the merger of our biological thinking and existence with our technology, resulting in a world that is still human but that transcends our biological roots. There will be no distinction, post-Singularity, between human and machine or between physical and virtual reality. If you wonder what will remain unequivocally human in such a world, it's simply this quality: ours is the species that inherently seeks to extend its physical and mental reach beyond current Limitations".

23 "No cabe duda de que la lectura ha constituido una gran potencia educadora de hombres -y, en dimensiones más modestas, todavía lo es-; pero, a pesar de ello, la selección, igual da de qué forma se realizará, siempre entraba en juego como el poder oculto tras el poder. Lecciones y selecciones tienen más que ver entre sí de lo que ningún historiador de la cultura haya jamás querido o podido pensar, y por mucho que hoy nos parezca de todo punto imposible reconstruir con suficiente exactitud esa relación entre leer y seleccionar, no deja de ser algo más que una mera sospecha no vinculante el hecho de que esta relación como tal posee una realidad propia" (Sloterdijk, 2006, p. 68).

${ }^{24}$ La conferencia de Sloterdijk constituye una lectura de la "Carta sobre el Humanismo" de Heidegger. En esta Heidegger lamenta la caída ("Verfall") del lenguaje como instrumento de dominación y poder. El problema parece ser que el lenguaje desde la tradición platónica y aristotélica ha ido de-generando en esa dirección hasta alcanzar los fundamentos metafísicos de la edad moderna. Como sostiene el propio Heidegger: "Pero la decadencia actual del lenguaje, de la que, un poco tarde, tanto se habla últimamente, no es el fundamento, sino la consecuencia del proceso por el que el lenguaje, bajo el dominio de la metafísica moderna de la subjetividad, va cayendo de modo casi irrefrenable fuera de su elemento. El lenguaje también nos hurta su esencia: ser la casa de la verdad del ser. El lenguaje se abandona a nuestro mero querer y hacer a modo de instrumento de dominación sobre lo ente" (Heidegger, 2010, p. 7). Los intérpretes concuerdan que el llamado de Heidegger en esta carta se enfoca a la responsabilidad de occidente de tiempos de postguerra. En este sentido que llama a volver a la casa del ser que constituye el lenguaje a partir de lo "indecible" ("Namen-los"). "Pero si el hombre quiere volver a encontrarse alguna vez en la vecindad al ser, tiene que aprender previamente a existir prescindiendo de nombres" (Heidegger, 2010, pp. 7-8). En esto parece enfocarse el esfuerzo de Heidegger al oponer su propio lenguaje, - centrado en el Dasein- con el lenguaje que funda el pensamiento moderno, cargado de distinciones de valor y uso, transformándose de esa forma el lenguaje en otro instrumento más de dominación y control de lo ente. El problema es que el control y la planificación nunca son totales, aunque pretendan incluir la totalidad de los acontecimientos de lo ente, amenazan con volcarse hacia su propio modo de existencia. En este sentido, la filosofía de Heidegger permite una entrada crítica hacia la separación ontológica que acontece en la temprana modernidad y que vuelve a ser problematizada en relación a la separación naturaleza y cultura.

${ }^{25}$ Hay que mencionar que con "creativo" no se pretende dar a este proceso un valor "positivo". La creatividad más bien debe entenderse como superación de las limitaciones de todo tipo en pos de cada vez más profundas transformaciones socioculturales, que en ocasiones involucran las propias definiciones del reino natural y por tanto, estas pueden re-configurar las propias relaciones con el "mundo biológico".

${ }^{26}$ Véase sobre todo las lecturas "biopolíticas" actuales sobre Nietzsche, como la interpretación de Vanessa Lemm en su libro La filosofía animal de Nietzsche. Cultura, política y animalidad del ser humano (2010).

27 Sloterdijk presenta la idea de las antropotécnicas contundentemente desarrollada años más tarde en el libro Debes cambiar tu vida (2004), donde su interpretación radica en sostener a la cultura (entendida en términos amplios como Cultura "con mayúscula"), como un dispositivo antropotécnico por excelencia. La idea de cultura de Sloterdijk es dar cuenta del vasto campo de posibilidades de la creatividad humana en sus aspectos materiales e inmateriales; desde el cultivo de los cuerpos (como en el caso de los juegos olímpicos), hasta las modificaciones del pensamiento humano (caso Foucault, Wittgenstein y Nietzsche). Desde esta visión la cultura se presenta como fundamentalmente creativa e innovadora, pero también como un "sistema de ejercicio". El carácter experimental de la cultura es signo también que el Hombre produce al Hombre, pero no únicamente a partir del trabajo (como sostiene la tradición marxista), sino a partir de constantes intentos y ejercicios, cuya carácter tecnológico y biopolítico implica tanto la permanente transformación de sus condiciones de existencia como también el rompimiento de las barreras naturales impuestas a su desarrollo.

${ }^{28}$ El problema es que, como nos señala Latour, como modernos y occidentales hemos sido presos de una ilusión que porta gran parte de nuestras definiciones y significaciones de un mundo ontológicamente segmentado. Pero si nos enfocamos a la práctica humana, veremos que lenguaje y perfomance actúan y coexisten en ámbitos distintos: una cosa es lo que decimos ser y otra cosa es cómo nos comportamos ante esta distinción. En esto radica, según Latour, gran parte del autoengaño del hombre moderno: ser moderno significa creer en una separación entre ámbitos ontológicos que en la práctica no funciona. Para una discusión detallada sobre las implicancias de este dualismo ontológico, el cual queda expresado en la separación entre ciencia y política, véase Shapin y Shaffer, Leviathan and the air pump (2011), Latour (2007). 
${ }^{29}$ Aquí me baso fundamentalmente en una noción clásica de ciencia: la pirámide de las ciencias (expuesta por el biólogo Steven Rose (2000)). En el cual, la ciencia "madre": la física, constituye la base del edificio, mientras que en los pisos superiores se sitúan las ciencias sociales: sociología y psicología. Las ciencias "duras" y "blandas" se sitúan en niveles respectivos de acuerdo al grado de incidencia y manipulación que puedan ejercer sobre lo observado. En este sentido, el objetivismo sigue siendo una creencia fundamental legitimadora del saber científico. Pero esta distinción "de niveles", diferenciados según los grados de "objetividad científica", en relación, a su vez, al nivel de involucramiento con su objeto de estudio, comporta hoy en día una serie de problemas. Uno de ellos, -y quizás el más interesante -, constituye la prestación conceptual que ocurre de forma unidireccional, desde el lado "duro" hacia el lado "blando", con conceptos como "entropía", "negentropía", "selección" o "autopoiesis". Respecto a este último concepto, que autores como Maturana manifiestan su preocupación por el "traslado" conceptual,

\section{Referencias bibliográficas}

Adhar Mall, R. \& Hülsmann, H. (1989). Die Drei Geburtsorte der Philosphie. China, Indien, Europa. Bonn: Bouvier.

Agar, N. (2016). Don't Worry about Superintelligence. Journal of evolution and technology. 26, 73-82.

Bateson, G. (1998). Pasos hacia una ecología de la mente. Buenos Aires: Lumen.

Bayerz, K. (2009). Hat der Mensch eine Natur? Und ist sie Wertvoll? En Martin Weiß. (comp.) Bios und Zoe. Die menschliche Natur im Zeitalter ihrer Reproduzierbarkeit. Frankfurt am Main: Suhrkamp Verlag.

Bergson, H. (2007). La evolución creadora. Buenos Aires: Cactus. Castoriadis, C. (2008). El mundo fragmentado. La Plata: Terramar.

Dawkins, R. (1993). El gen egoísta. Barcelona: Salvat Editores, S.A.

Deacon, T. (1997). The simbolic Species. The co-evolution of lenguage and the brain. New York: Norton \& company Inc.

Descola, P. \& Pálson, G. (Comp.) (2001). Naturaleza y sociedad. Perspectivas antropológicas. México D.F.: Siglo XXI.

Drexler, E. (1986). Engines of Creation the Coming Era of Nanotechnology. New York \& Toronto: Anchor Books. Random House Inc.

Ellen, R. (2001). La geometría cognitiva de la naturaleza. Un enfoque contextual. En Descola, P. \& Pálson.G. (Comp.) Naturaleza y sociedad. Perspectivas antropológicas. México D.F.: Siglo XXI.

Foucault, M. (2003). Las palabras y las cosas. Una arqueología de las ciencias humanas. Buenos Aires: Siglo XXI

Fukuyama, F. (2004). El transhumanismo. Disponible en: http:// www.fp-es.org/oct_nov_2004/story_5_9.asp. Fecha de consulta 8 de enero 2007 de una ciencia a otra. "Sin duda que la noción de autopoiesis ha sido atractiva para muchas personas que la han usado bastante como sinónimo de auto-organización, o como evocadora de procesos auto-sustentables. A mí esto no me gusta mucho, particularmente cuando se usa la noción de autopoiesis en el ámbito de lo social. Las palabras pueden ser evocadoras e inspiradoras, pero también pueden ser ocultadoras cuando no se conectan adecuadamente con los procesos que se supone coordinan en su concepción primaria" (Maturana, 2014, p. 8).

${ }^{30}$ Como sostiene el Filósofo alemán Kurt Bayertz: "La idea de la "naturaleza humana" es una especie de oxímoron. Porque es una característica de la "naturaleza" del ser humano, que no solo está sujeto al cambio evolutivo (tal como los animales), sino que se transforma a sí mismo; en este sentido, es "de naturaleza artificial". Por ello, su naturaleza, no es algo estable y constante, sino más bien algo alterable. Más bien, ella misma es auto alterable" (Bayertz. 2009, p. 104).
Gould, S. (1983). Desde Darwin. Reflexiones sobre historia natural. Madrid: Herman Blume ediciones.

Habermas, J. (2002). El futuro de la naturaleza humana. ¿Hacia una eugenesia liberal? Barcelona: Editorial Paidós.

Haraway, D. (1995). Die Neuerfindung der Natur. Primaten, Cyborgs und Frauen. Frankfurt a. M. \& New York: Campus.

Hayles, K. (1999). How we became posthuman. Virtual bodies in cybernetics, literature and informatics. Chicago: The university of Chicago press.

Heidegger, M. (2015). Holzwege. Frankfurt am Main: Klosterman. (2010). Über den Humanismus. Frankfurt am Main: Vittorio Klostermann.

Kuryweil, R. (2008). The singularty is near. When human transcendend biology. London: Duckworth Overlook.

Latour, B. (2007). Nunca fuimos modernos. Ensayo de antropología simétrica. Buenos Aires: Siglo XXI editores.

(2010). Das Parlament der Dinge. Frankfurt am Main:

Suhrkamp Verlag.

Lemm, V. (2010). La filosofía animal de Nietzsche. Cultura, política y animalidad del ser humano. Santiago de Chile: Editorial UDP.

Lewontin, R., Rose, S. \& Kamin, L. (1987). No está en los genes. Racismo, genética e ideología. Barcelona: Editorial Crítica.

Jonas, H. (1984). Das Prinzip Verantwortung. Versuch einer Ethik für die Technologische Zivilisation. Frankfurt am Main: Suhrkamp.

Maturana, H. \& Varela, F. (2003). De máquinas y seres vivos. Autopoiesis: La organización de lo vivo. Buenos Aires: Editorial Lumen.

Maturana, H. (2014). ¿Cuál es la contribución histórica de la noción de autopoiesis? Le monde diplomatique, XIV(148), 8-9. 
Mayr, E. (1992). Una larga controversia. Darwin y el darwinismo. Barcelona: Grijalbo.

Minsky, M. (1986). La sociedad de la mente. La inteligencia humana a la luz de la inteligencia artificial. Buenos Aires: Ediciones Galapago.

Monod, J. (1993). El azar y la necesidad. Barcelona: Planeta Agostini.

Rose, S. (2000). Darwins gefährliche Erben. Biologie Jenseits der egoistischen Gene. München: C.H. Beck Verlag

Shapin, S. \& Schaffer, S. (2011). Leviathan and the Air-Pump. Hobbes, Boyle and the Experimental Life. Princeton: Princeton University Press.

Shiva, V. (2003). ¿Proteger o expoliar? Los derechos de propiedad intelectual. Barcelona: Ediciones Octaedro.
Sibilia, P. (2009). El hombre postorgánico. Cuerpo, subjetividad y tecnología digitales. Buenos Aires: F.C.E.

Sloterdijk, P. (2006). Normas para el parque humano. Una respuesta a la carta sobre el humanismo de Heidegger. Madrid: Ediciones Siruela.

(2009). Du mußt dein Leben ändern. Frankfurt am Main:

Suhrkamp Verlag.

Torreti, R. (2010). La proliferación de los conceptos de especie en la biología evolucionista. Revista THEORIA 69, 325-377.

Virilio, P. (1996) Die Eroberung des Körpers. Frankfurt am Main: Fischer Verlag. 